www.jmscr.igmpublication.org

Impact Factor (SJIF): 6.379

Index Copernicus Value: 79.54

ISSN (e)-2347-176x ISSN (p) 2455-0450

crossrefDOI: https://dx.doi.org/10.18535/jmscr/v6i10.169

Journal Of Medical Science And Clinical Research

IGM Publication

An Official Publication of IGM Publication

\title{
A Study of Clinical Profile in Neonatal Seizures with Special Reference to Biochemical Abnormalities at NICU, RMMCH, Chidambaram
}

\author{
Authors
Dr G. Surendiran ${ }^{1 *}$, Dr S. Ramesh ${ }^{2}$, Dr S. Saravanan ${ }^{3}$, Dr S. Chidambaranathan ${ }^{4}$, Dr Praveen Kumar ${ }^{5}$ \\ ${ }^{* 1}$ Post Graduate, Department of Pediatrics, Rajah Muthiah Medical College, Chidambaram \\ ${ }^{2}$ Professor and Head, Department of Pediatrics, Rajah Muthiah Medical College, Chidambaram \\ ${ }^{3,4}$ Associate Professor, Department of Pediatrics, Rajah Muthiah Medical College, Chidambaram \\ ${ }^{5}$ Lecturer, Department of Pediatrics, Rajah Muthiah Medical College, Chidambaram \\ Corresponding Author
}

Dr S. Saravanan

Email: paedssaravanan@gmail.com

\begin{abstract}
Objectives: To study the presentation of seizures in neonate with special reference to clinical etiology and metabolic abnormalities. This study aims to find the etiology, metabolic abnormalities and time of onset in newborn presenting with neonatal seizures in NICU Rajah Muthaih Medical College.

Materials and Methods: This is prospective, observational hospital based study. This study include Hundred neonates, who had seizures within 28 days from birth admitted in Rajah Muthaih Medical College neonatal intensive care unit, were observed for etiological factor, clinical varient and metabolic abnormalities found in neonatal seizure.

Results: The result observed are subtle seizure forms the most common seizure, followed by clonic seizure [focal (25\%), multifocal (12.5\%). Tonic type of seizure in (7.5\%) and myoclonic in (5\%). Among metabolic abnormalities hypoglycaemia was found in (22\%) and hypocalcaemia in (11\%), followed by hyponatremia and hypokalemia Birth asphyxia is the most common cause of seizures, followed by infection and metabolic cause.
\end{abstract}

Keywords: Neonatal seizure, hypoglycaemia, clonic seizure, Birth asphyxia.

\section{Introduction}

The neonatal seizure needed to be treated aggressively in order to prevent the neurological complication at later stage of life. Metabolic abnormalities are usually associated with the underlying hypoxia and infection. Hence in all cases of neonatal seizures with biochemical abnormalities underground screening is needed.

Seizures in neonatal period are more common in preterm babies when compared to the term babies.
Very low birth weight ${ }^{6}$ and low birth weight babies have increased chances of seizures when compared to term, adequate weight for gestational age.

\section{Materials and Methods}

This study is conducted in Rajah Muthiah Medical College between November 2016 to October 2018. 
Neonates presented with seizure within 28 days of life are included in the study. Total 100 cases of neonatal seizure presenting before 28 days of life was included in the study. Age, sex, etiological factors and biochemical parameters were recorded.

\section{Results}

There were 1737 live births during the study period between November 2016 to October 2018, out of which 100 neonates with seizure with complete etiology and follow up are taken into the study.

The seizures were more common in male babies compared to female babies observed in the study.

1. Birth asphyxia and perinatal asphyxia within 3days of life is the commonest cause of seizure, followed by infection. ${ }^{5}$

2. Hypoglycaemia is the most common metabolic abnormality, followed by hypocalcemia, hyponatremia and hypokalemia.

\section{Discussion}

Distribution of etiology in study

\begin{tabular}{|l|c|c|}
\hline Diagnosis & $\begin{array}{c}\text { Gabriel et al } \\
(\mathbf{n = 9 0 )} \%\end{array}$ & $\begin{array}{c}\text { Present study } \\
(\mathbf{n = 1 0 0 )} \%\end{array}$ \\
\hline HIE & 40 & 42 \\
\hline Infections & 20 & 25 \\
\hline Metabolic & 19 & 20 \\
\hline
\end{tabular}

\section{Metabolic work up}

In metabolic work up 34 neonates had hypoglycemia, of which 15 neonates had isolated hypoglycemia while the remaining 19 neonates were associated with septicemia and HIE. ${ }^{1}$ Out of 15 neonates with hypocalcemia, 4 neonates had isolated hypocalcemia and remaining 11 neonates were associated with other conditions. There was only one neonate with hypomagnesemia.

\begin{tabular}{|l|c|}
\hline Hypoglycemia & 34 \\
\hline Hypocalcemia & 15 \\
\hline Hypomagnesemia & 1 \\
\hline Hyponatremia & 5 \\
\hline
\end{tabular}

\section{Seizure type and etiology}

Out of 55 neonates with subtle seizure, the most common etiology was HIE $(67 \%))^{2-5} 4$ neonates had infective etiology (13\%). 50\% of multifocal clonic type of seizure were due to infection (23 neonates) and $41 \%$ due to metabolic etiology (19 neonates). Out of 32 neonates with focal clonic type of seizure, ${ }^{2-4} 44 \%$ were due to metabolic etiology and $50 \%$ of due to infection. Out of 19 neonates with generalized tonic type of the seizure, $31 \%$ were due to ICH and $47 \%$ were due to HIE.

\begin{tabular}{|l|c|c|}
\hline Etiology & Term (61) & Preterm (39) \\
\hline HIE & $40(95 \%)$ & $2(5 \%)$ \\
\hline Infection & $12(48 \%)$ & $13(52 \%)$ \\
\hline Metabolic & 10 & 10 \\
\hline ICH & - & 6 \\
\hline Hydrocephalous & 2 & - \\
\hline Kernicterus & - & 1 \\
\hline Unknown & 3 & 1 \\
\hline
\end{tabular}

\section{Seizure types and etiological factors for different seizures}

\begin{tabular}{|l|c|c|c|c|c|c|}
\hline Types & HIE & Infection & Metabolic & Hyd. & Ker. & Unk. \\
\hline Subtle (27) & $18(67 \%)$ & $4(13 \%)$ & $12(47 \%)$ & - & 1 & 1 \\
\hline Focal clonic (16) & $1(6 \%)$ & $8(50 \%)$ & $7(44 \%)$ & - & - & - \\
\hline Multifocal clonic (23) & $4(9 \%)$ & $12(50 \%)$ & $8(41 \%)$ & - & - & - \\
\hline Focal tonic (6) & $3(42 \%)$ & - & - & - & - & $1(8 \%)$ \\
\hline Generalized tonic (8) & $5(47 \%)$ & - & - & $1(11 \%)$ & 1 & 1 \\
\hline Myoclonic (2) & - & - & - & - & - & 2 \\
\hline
\end{tabular}

\section{Natal factors}

Out of 100 neonates included in this study, $42 \%$ of neonates had history of birth asphyxia, $39 \%$ had fetal distress and $21 \%$ had PROM. ${ }^{8}$ 


\section{Distribution by Natal Factors}

\begin{tabular}{|l|c|c|}
\hline Natal factors & No. of neonates & Percentage \\
\hline Fetal distress & 39 & $39 \%$ \\
Birth asphyxia & 42 & $42 \%$ \\
Prolonged labour & 19 & $19 \%$ \\
CPD & 15 & $15 \%$ \\
MSAF & 19 & $19 \%$ \\
PROM & 21 & $21 \%$ \\
Cord around the neck & 6 & $6 \%$ \\
Abnormal lie & 3 & $3 \%$ \\
\hline
\end{tabular}

Incidence of neonatal seizure according to age of onset

Commonest cause of seizure in first day of life was HIE $(25 \%)$. Between $2-3^{\text {rd }}$ day, $17 \%$ of neonates with HIE and $12 \%$ of neonates with metabolic cause had seizures. Between $4-8^{\text {th }}$ days of life, the predominant cause for seizure was infection $16 \%$ and $6 \%$ of neonates with infection had seizure between $9-28^{\text {th }}$ days. ${ }^{15}$
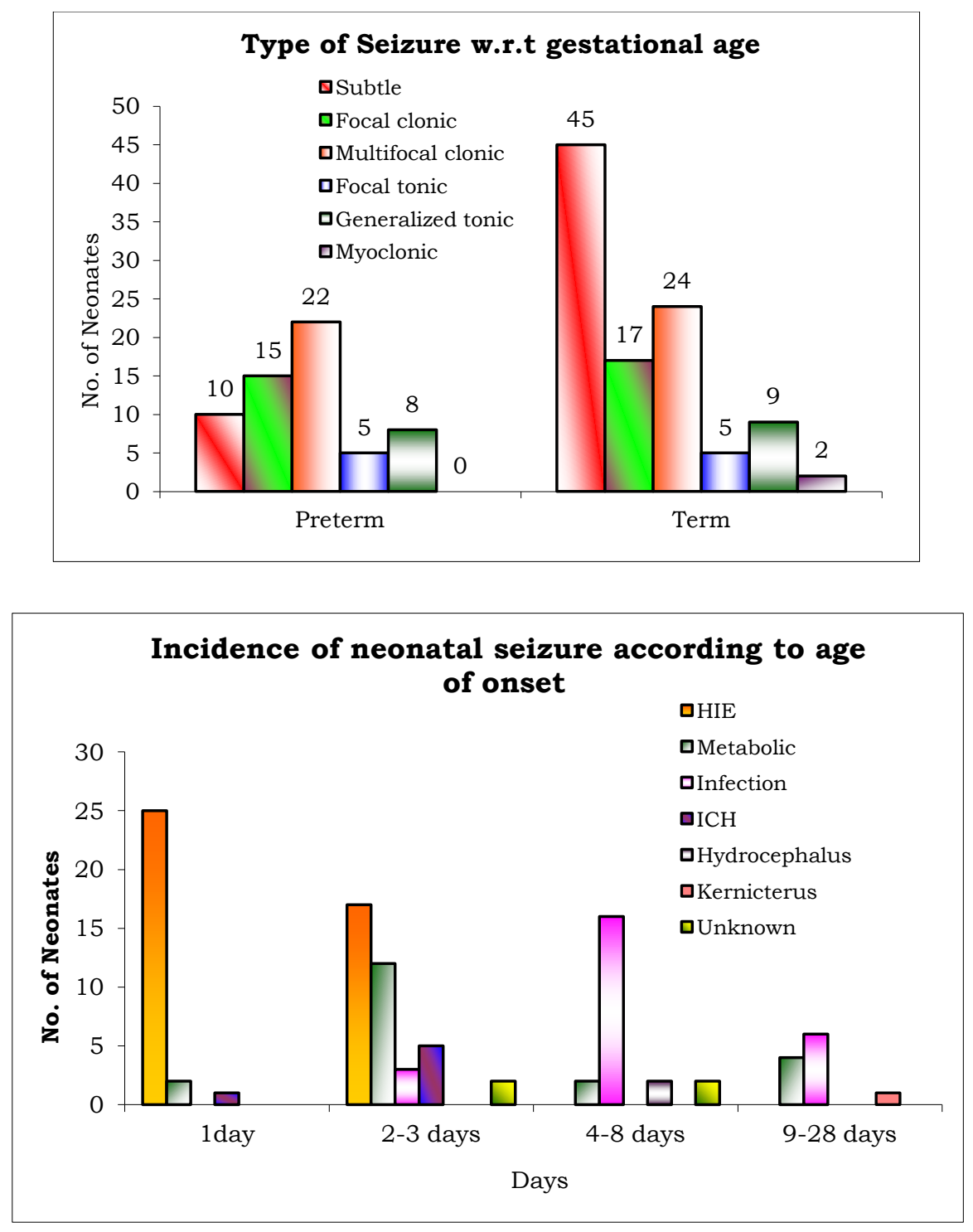

\section{Antenatal factors}

Out of 100 mothers 82 mothers had regular Antenatal checkup and was immunized against tetanus. 52 mothers had anemia, 26 mothers had infection and 16 mothers had $\mathrm{PIH}{ }^{7}$ 
Distribution by Antenatal Factors

\begin{tabular}{|l|c|c|}
\hline ANF & No. of mothers & Percentage \\
\hline ANC & 82 & $82 \%$ \\
TT & 82 & $82 \%$ \\
Anemia & 52 & $52 \%$ \\
Diabetes & 6 & $6 \%$ \\
PIH & 16 & $16 \%$ \\
APH & 5 & $5 \%$ \\
Multiple Gestation & 10 & $10 \%$ \\
Infection & 26 & $26 \%$ \\
Cardiac Disease & 5 & $5 \%$ \\
Oligohydramnios & 3 & $3 \%$ \\
Epilepsy & 4 & $4 \%$ \\
\hline
\end{tabular}

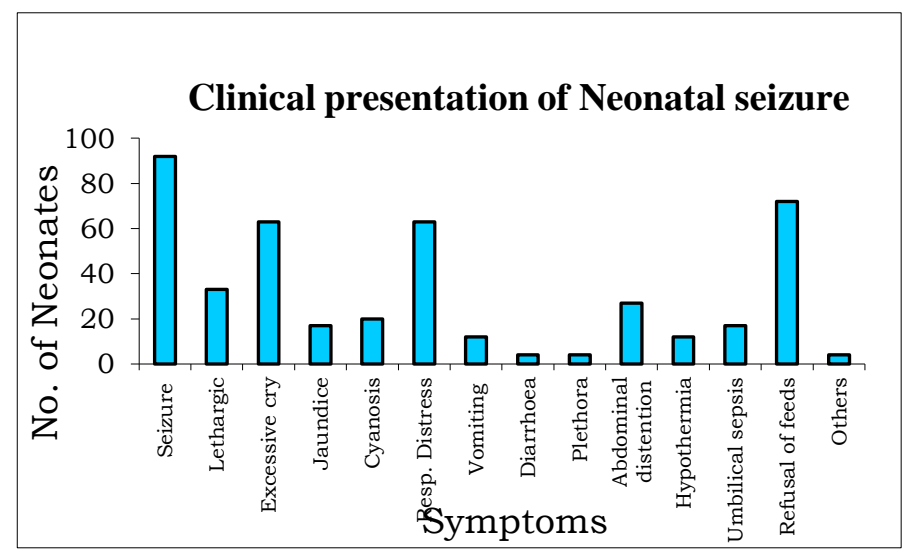

\section{Age and Seizures}

Out of 100 neonates the maximum no. of neonates had seizures between 24 to $74 \mathrm{hrs} \mathrm{(39 \% )} \mathrm{followed}$ by $28 \%$ of neonates had seizures within $24 \mathrm{hrs}$. $22 \%$ of neonates had seizure between 4 to 7 days and $11 \%$ of neonates had seizure beyond $1^{\text {st }}$ week of life. ${ }^{12-14}$

\section{Sex incidence}

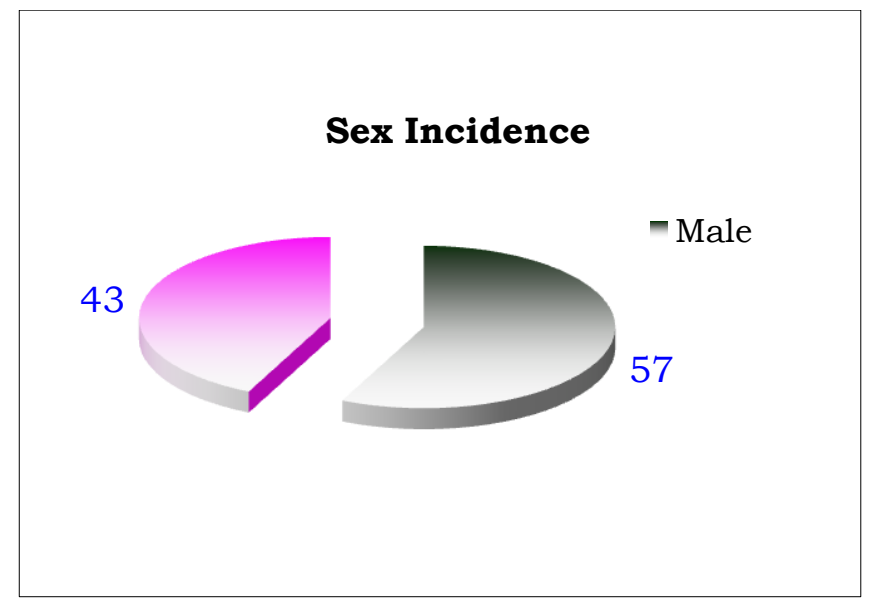

\section{Time of Onset of Seizures}

\begin{tabular}{|l|c|c|}
\hline Age & No. of Neonates & Percentage \\
\hline$<24$ hrs & 28 & $28 \%$ \\
\hline 24-72hrs & 39 & $39 \%$ \\
\hline 4-7days & 22 & $22 \%$ \\
\hline 8-28days & 11 & $11 \%$ \\
\hline
\end{tabular}

In CNS examination, neonatal reflexes were normal in 30 neonates and absent in 30 neonates. 31 neonates had decreased neonatal reflexes and increased neonatal reflexes in 9 neonates. ${ }^{6}$

With regards to muscle tone, 27 neonates were normal. Decreased muscle tone was seen in 61 neonates and increased muscle tone in 12 neonates.

\section{CNS Outcome}

\begin{tabular}{|l|c|c|c|}
\hline & Findings & $\begin{array}{c}\text { No. of } \\
\text { seizures }\end{array}$ & Percentage \\
\hline \multirow{4}{*}{$\begin{array}{l}\text { Neonatal } \\
\text { reflex }\end{array}$} & Normal & 30 & $30 \%$ \\
\cline { 2 - 4 } & Increased & 9 & $9 \%$ \\
\cline { 2 - 4 } & Decreased & 31 & $31 \%$ \\
\cline { 2 - 4 } & Absent & 30 & $30 \%$ \\
\hline \multirow{4}{*}{ Tone } & Normal & 27 & $27 \%$ \\
\cline { 2 - 4 } & Increased & 12 & $12 \%$ \\
\cline { 2 - 4 } & Decreased & 61 & $61 \%$ \\
\hline
\end{tabular}

\section{CRP study}

Blood CRP had been done in all 100 cases, out of which 27 were positive. Out of 25 suspected septicemia cases, 23 were positive. ${ }^{8-10}$

\section{Distribution of Positive CRP}

\begin{tabular}{|l|c|c|c|}
\hline Specimen & $\begin{array}{c}\text { No. of } \\
\text { neonates }\end{array}$ & Positive & Negative \\
\hline Blood & 100 & 27 & 63 \\
\hline Septicemia & 25 & 23 & 2 \\
\hline
\end{tabular}

\section{Conclusion}

1) Seizures are multi-factorial in etiology and HIE is the commonest cause followed by infections and metabolic causes. ${ }^{11}$

2) In metabolic causes, Hypoglycemia is the most common biochemical abnormality, followed by hypocalcemia

3) Clinically, subtle seizure activity is more commonly observed followed by clonic type. 
4) During the entire neonatal period, seizures are more commonly seen in the first week of life.

5) Hypoglycemia and hypocalcemia are mostly associated with HIE

6) Metabolic causes of seizures carry the good prognosis if treated promptly

7) Neonates with subtle seizures are more likely to be normal at discharge. Tonic seizures have the highest morbidity and mortality, among all seizure types.

8) HIE carries the worst prognosis and the metabolic causes carry good prognosis, among all etiological factors for seizure.

\section{Reference}

1. Jensen FE. Developmental factors regulating susceptibility to perinatal brain injury and seizures. Curr Opin Pediatr 2006;18(6):628-33.

2. Rahman $\mathrm{S}$, et al. Inborn errors of metabolism causing epilepsy. Dev Med Child Neurol. 2013;55(1):23-36.

3. Uria-Avellanal C, Marlow N, Rennie JM. Outcome following neonatal seizures. SeminFetal Neonatal Med. 2013.

4. Rakhade SN, Jensen FE. Epileptogenesis in the immature brain: emerging mechanisms. Nat Rev Neurol. 2009; 5(7):380-91.

5. Dzhala VI, Staley KJ. Excitatory actions of endogenously released GABA contribute to initiation of ictal epileptiform activity in the developing hippocampus. J Neurosci. 2003;23(5):1840-6.

6. Temko A, et al. Robust neonatal EEG seizure detection through adaptive background modeling. Int $\mathrm{J}$ Neural Syst. 2013; 23(4):1350018.
7. Temko A, et al. Inclusion of temporal priors for automated neonatal EEG classification. J Neural Eng. 2012; 9(4):046002.

8. Slaughter LA, Patel AD, Slaughter JL. Pharmacological treatment of neonatal seizures: a systematic review. J Child Neurol. 2013;28(3):351-64

9. Lynch NE, et al. The temporal evolution of electrographic seizure burden in neonatal hypoxic ischemic encephalopathy. Epilepsia. 2012;53(3):549 $-57$

10. Glass HC, et al. Neonatal seizures: treatment practices among term and preterm infants. Pediatrv Neurol. 2012; 46(2):111-5

11. Talos DM, et al. Antiepileptic effects of levetiracetam in a rodent neonatal seizure model. Pediatr Res. 2013; 73(1):24-30.

12. Kilicdag $H$, et al. The effect of levetiracetam on neuronal apoptosis in neonatal rat model of hypoxic ischemic brain injury. Early Hum Dev. 2013; 89(5): 355-60.

13. Sharpe CM, et al. A seven-day study of the pharmacokinetics of intravenous levetiracetam in neonates: marked changes in pharmacokinetics occur during the first week of life. Pediatr Res. 2012; 72(1):4.

14. Lundqvist M, et al. Efficacy and safety of lidocaine for treatment of neonatal seizures. Acta Paediatr. 2013; 102(9): 863-7.3-9.

15. Clark AM, et al. Intravenous topiramate: Comparison of pharmacokinetics and safety with the oral formulation in healthy volunteers. Epilepsia. 2013;54(6):1099105. 